\title{
On the Role of Complexity for Guiding Enterprise Transformations
}

\author{
Jannis Beese, Stephan Aier and Robert Winter \\ Institute of Information Management, University of St.Gallen, Switzerland \\ \{jannis.beese, stephan.aier, robert.winter\}@unisg.ch
}

\begin{abstract}
While there is a general agreement on the need for tools, which guide the evolution of complex organizational systems, and while there already exists a wealth of tools and approaches for the measurement and management of complexity, it seems that in practice these approaches often fail to achieve the desired impact during transformation processes. Based on focus group data and based on related literature, we analyze the factors that hinder current complexity management systems from guiding enterprise transformations and contribute a set of design principles, which address these factors. In particular, it is important to be aware of the context, to use a consistent ontology, to pay attention to visualization and to raise awareness and support.
\end{abstract}

Keywords: Complexity, complexity management, complexity measurement, enterprise transformation

\section{Introduction}

Large enterprises need to continuously undergo transformation in order to adapt to varying external conditions. For large enterprises transformations comprise a series of local changes within the organization in order to cope with new and evolving requirements $[1,2]$. While these local adaptations manage to temporarily fulfill the requirements, a series of such changes across different parts of the organization leads to unplanned and suboptimal states of the entire organization as a whole [3]. Inconsistencies, unnecessary redundancies or dependencies are introduced, which are typical drivers of complexity. This complexity in turn prevents people from recognizing a not only locally but globally optimal way to adapt and hinders efficient operation in the resulting state. Thus, there is a sustained practical [4-6] and academic [7-9] interest in complexity management and the development of underlying complexity measurement systems, which assist businesses in guiding transformations in a way that avoids unnecessary complexity.

There are multiple and diverse understandings of complexity [10-13] and the criteria for recognizing and measuring it vary both in terms of perspective and context [14-16]. Therefore, guidance on a higher level is required in order to coordinate developments within large enterprises with regard to complexity, so that inconsistencies and unnecessary redundancies are avoided or removed [17-20]. Resulting complexity 
management methods rely on measurement systems that assess the current situation and evaluate the success of ongoing transformations [21].

However, it still seems that these complexity measurement systems often fail to achieve the desired impact during enterprise transformations: Various case studies show, that complexity management is considered important, yet not adequately supported $[4,6,22]$. For example, ATKearney report $84 \%$ of companies recognizing complexity as a key cost driver, but these companies do not feel that they have "sufficient tools and systems to ensure continuous monitoring and controlling of complexity" [22].

This disparity between the effort spent on complexity measurement and management systems, and their perceived impact leads to the following research question:

Which principles should guide the design of complexity measurement systems in order to be useful for steering enterprise transformations?

We use a design science method following Peffers et al. [23] to tackle this question. Following Fischer [24], an abductive approach, based on focus group data, literature and conceptual analysis, is used to construct a set of design principles as target artifacts [25]. In order to identify and motivate our problem, we first identify seven factors that hinder complexity measurement systems from being used as guidance for enterprise transformations. We then propose four design principles for complexity measurement systems, which attempt to address these factors.

The rest of this paper is organized as follows: In Section 2 the conceptual foundations are laid out and an overview of related work is given, focusing on actual approaches to measuring and managing complexity. Building on these frameworks, in Section 3 a set of factors that inhibit their operationalization is presented and analyzed. This is used in Section 4 in order to derive a set of principles, which should guide the design and operationalization of complexity measurement and management systems in organizations. Section 5 discusses the scope and applicability of these principles, their limitations and potential implications, and gives an outlook on future work.

\section{Conceptual Foundations and Target Artifact}

In this paper we focus on the impact of complexity measurement on enterprise transformations. Measurement is not a goal in itself though, so in order to evaluate the effect it needs to be integrated in complexity management and organizational/structural decision processes that aim at sustaining a business's ability to act efficiently, by transforming it in response to new requirements. This also makes sense from the other perspective: Complexity management methods rely on measurement systems in order to assess the current situation and in order to evaluate the success of current transformations [21].

In the context of this research, i.e. in dealing with large enterprises, complexity is in essence a human problem, meaning the inability of a person to make decisions and to take corresponding actions that guide the enterprise as a whole towards a globally optimal state due to too much or too complex information $[15,26]$. While this interpretation differs distinctly from some descriptive and rather technical definitions 
(e.g. space or running-time complexity), it extends to the usual complexity measures for organizational and IS structures [16] in a natural way: An organizational entity, or a model thereof, with, for example, more components and relations among them, is often harder to analyze and understand, so that it will in turn be more difficult for a decision-maker to make the appropriate changes and to transform the overall system in an efficient and effective way. A typical example is the recognition and removal of unnecessary redundancies: It is hard from a local perspective to identify whether a given object is redundant or what the effects of its removal on the entire organization would be.

The reason for taking this perspective on complexity is that the target artifact of this research is not a precise definition of complexity, but an explanation of why the currently employed tools and methods often fail to achieve the desired impact during enterprise transformations and how this can be addressed.

Complexity measurement and management are generally employed to make businesses more agile, efficient, or robust, and to this end there exist very elaborate frameworks which support these goals in different environments or on different levels of the organizational hierarchy [21]. The design and implementation of these measurement and structural models are dependent on the context, defined by

(1) the objects to be evaluated (e.g. IS complexity, organizational complexity, task complexity or product complexity)

(2) the targeted users (e.g. IT managers, product designers, department heads, steering committees or enterprise architects)

(3) the goals of complexity management (e.g. agility, efficiency or robustness)

(4) environmental factors (e.g. industry factors, technological advances or market factors).

A good overview of common approaches to complexity measurement of different organizational entities is given in [16]. Even within a given category of objects, the differences in the operationalization of the measures are evident ([16], pp.49-51). Additionally, a number of researchers are using ideas and analogies from cybernetics and complexity theory for analyzing complex systems in businesses, and although these approaches are not without criticism (cf. [27]), they introduce another set of very different ideas and approaches [8-10, 28, 29]. It is an important but difficult task to combine these approaches in a structured way to coherent ontological models [30].

Similar concepts exist for the management of complex projects, which aim at providing structured approaches for dealing with complexity or at reducing unnecessary complexity [18-20]. Recognizing and analyzing the given internal and environmental complexity is a prerequisite for the effective application of these techniques.

Different goals, design approaches, scopes and external factors lead to this diverse set of tools and methods. Therefore it does not seem appropriate to develop a "one-sizefits-all" solution for dealing with complexity [31]. Instead, multiple approaches can coexist within one organization, for example in order to deal with differences from

- necessary or external versus unnecessary or internal complexity

- "difficult", "complex" and "chaotic" systems [32]

- innovative and stable environments [33, 34]. 
These approaches, however, still need to be implemented, executed, supported and communicated in a coherent way in order to achieve maximum impact. We therefore propose a set of design principles, which serve as a guideline for these processes.

\section{Analysis of the Problems of Complexity Measurement Tools}

An analysis of the gap between the status quo of complexity measurement and management systems, and their perceived impact lends itself to a design and evaluation process involving focus groups: Experts from different organizations need to be involved in order to avoid the target artifact being only applicable in a specific case, but the nature of the research question calls for a deeper understanding and discussion [35, 36]. Hevner and Chatterjee ([35], pp.123-124) point out, that a design science research approach involving focus groups

- allows "the researcher to clarify any questions about the design artifact as well as probing the respondents on certain key design issues",

- allows "deeper understandings, not only on the respondents' reaction and use of the artifact but also on other issues that may be present in a business environment that would impact the design" and

- allows "the emergence of ideas or opinions that are not usually uncovered in individual interviews",

all of which are important requirements for this research.

A series of three two-day workshops was held during June 2014 and February 2015 involving 16, 13 and 13 enterprise architects and high-level IT managers from ten different companies, respectively. The companies were mostly operating in banking and insurance, but also in logistics and utilities. According to the Global Brand Simplicity Index, the insurance industry is by far the most complex industry, with utilities and banking not too far behind ([37], p.16). The size of the focus group allowed for an analysis of different ideas and viewpoints, while still being small enough for an in-depth discussion of more complicated questions. While the first two workshops were of an exploratory nature, with a focus on identifying, analyzing and grouping complexity factors, the final workshop had a confirmatory focus on evaluating potential solutions.

We identified a set of seven factors, which hinder the effective usage of complexity measurement and management systems. For every such factor we now explain the reasoning behind it before stating it together with a description, an example and any practical implications.

As complexity arises not as a local phenomenon that is easy to understand and explain, but instead results from the interactions that occur in larger systems, the attempts at making it tangible and manageable often exhibit the same complexity: The assessment process is difficult, involves diverse inputs and the resulting evaluations are hard to understand, interpret and communicate [14-16]. This in turn prevents people from using such tools during decision processes. 
Table 1. Factor: Complexity of the measurement system

\begin{tabular}{|l|l|}
\hline \multicolumn{2}{|c|}{ 1. Complexity of the measurement system } \\
\hline Description & The measurement systems themselves are difficult to understand. \\
\hline Example & $\begin{array}{l}\text { Organizations provide various perspectives on complexity (e.g. IT, } \\
\text { strategy, organizational) with different, complicated models that } \\
\text { comprise aggregated and calculated measures, which are hard to } \\
\text { explain and comprehend. }\end{array}$ \\
\hline Implication & $\begin{array}{l}\text { A large effort is required in order to understand and use the } \\
\text { measurement system. The system is only accessible for a small } \\
\text { group of users. Most people are not able to support their actions } \\
\text { with it or even avoid using the system altogether. }\end{array}$ \\
\hline
\end{tabular}

There is only a very general agreement on the concept of complexity, which varies among people with different backgrounds [10-13]. When building measurement and management systems this lack of a common understanding leads to different interpretations of the same terminology. This in turn makes the design process more difficult and later on makes it hard to communicate justifications based on the resulting systems.

Table 2. Factor: Unclear terminology

\begin{tabular}{|l|l|}
\hline \multicolumn{2}{|c|}{ 2. Unclear terminology } \\
\hline Description & $\begin{array}{l}\text { Terminology is used differently by different people or in different } \\
\text { contexts. }\end{array}$ \\
\hline Example & $\begin{array}{l}\text { Often classification leads to problems: To which area or category } \\
\text { does a given object or measure belong? Another example is that } \\
\text { the precise understanding of typical goals of complexity } \\
\text { management, such as agility or flexibility, often varies. }\end{array}$ \\
\hline Implication & $\begin{array}{l}\text { Decisions based on the obtained assessments are hard to } \\
\text { communicate and its usefulness for the evaluation of potential } \\
\text { actions will be limited. }\end{array}$ \\
\hline
\end{tabular}

Since complexity is an emergent property with interrelated causes, it is often hard or even impossible to find a definite indicator of complexity, which in all cases is apt for the given intent $[10,29]$. Thus there exist very different measures, but their applicability depends both on the context and the specific goals [16]. In practice though, existing measures are often applied without considering their aptitude.

Table 3. Factor: Measures inapt for goals

\begin{tabular}{|l|l|}
\hline \multicolumn{2}{|c|}{ 3. Measures inapt for goals } \\
\hline Description & $\begin{array}{l}\text { The operationalized measures are not feasible or their relations to } \\
\text { the targeted goals are unclear or not defined. }\end{array}$ \\
\hline Example & $\begin{array}{l}\text { Are lines of code an adequate measure for software complexity and } \\
\text { what can be achieved based on that measure? Is size (e.g. amount } \\
\text { of data) really relevant in all contexts, or only for certain } \\
\text { organizations, services or products? }\end{array}$ \\
\hline
\end{tabular}




\begin{tabular}{|l|l|}
\hline Implication & $\begin{array}{l}\text { The resulting assessments do not match the purpose. People are } \\
\text { not able to support decisions with assessments from the } \\
\text { measurement system and show resistance against its usage and } \\
\text { operation. }\end{array}$ \\
\hline
\end{tabular}

Often some indicators for complexity are difficult to measure. The reasons vary and frequently include problems with data ownership, undocumented or outdated information, missing cooperation from stakeholders or general efforts and costs required.

Table 4. Factor: Ability to obtain measures

\begin{tabular}{|l|l|}
\hline \multicolumn{2}{|c|}{ 4. Ability to obtain measures } \\
\hline Description & $\begin{array}{l}\text { Gathering certain measures requires inadequate effort or relies on } \\
\text { missing coordination and cooperation. }\end{array}$ \\
\hline Example & $\begin{array}{l}\text { Is there up-to-date information available which will be maintained } \\
\text { in the future? Often data is not voluntarily shared. } \\
\text { How does one measure dependencies or connectedness? Is this } \\
\text { data available? }\end{array}$ \\
\hline Implication & $\begin{array}{l}\text { The measurement systems cannot be developed and operated as } \\
\text { originally planned and defined. }\end{array}$ \\
\hline
\end{tabular}

As mentioned in Section 2, differences in the observed systems and the resulting properties as well as differences in the pursued goals lead to very diverse approaches to measurement and management [14-16]. This is a problem if the resulting tools are structured and presented in an inconsistent fashion, thus making it hard to compare and act upon the obtained results.

Table 5. Factor: Inconsistent presentation

\begin{tabular}{|l|l|}
\hline \multicolumn{2}{|c|}{ 5. Inconsistent presentation } \\
\hline Description & $\begin{array}{l}\text { Complexity assessments for different systems use a different } \\
\text { presentation or different scales. }\end{array}$ \\
\hline Example & $\begin{array}{l}\text { Often several dashboards report complexity assessments for } \\
\text { different areas, but they use different scales for the results, a } \\
\text { different color coding or different layouts. }\end{array}$ \\
\hline Implication & $\begin{array}{l}\text { It is hard to communicate results and compare different options } \\
\text { and systems. }\end{array}$ \\
\hline
\end{tabular}

Not being easily tangible and inherently hard to measure, systematic approaches for dealing with and evaluating complexity are often seen as unnecessary overhead or unwelcome monitoring. Furthermore, as these approaches span large parts of an organization, it is often unclear who is responsible for the continuous operation and development and for obtaining the required measures. This lack of support and responsibilities also leads to a very limited visibility of existing assessments and reports. 
Table 6. Factor: Lack of support and awareness

\begin{tabular}{|l|l|}
\hline \multicolumn{2}{|c|}{ 6. Lack of support and awareness } \\
\hline Description & $\begin{array}{l}\text { People are unwilling to support the operation and development of } \\
\text { complexity measurement systems or are unaware of existing } \\
\text { reports. They doubt the general benefit or are afraid of potential } \\
\text { changes and implications. }\end{array}$ \\
\hline Example & $\begin{array}{l}\text { As complexity measurement systems initially introduce an } \\
\text { additional effort for their construction and operation, people are } \\
\text { unwilling to support these systems. Often there is a general } \\
\text { resistance against a systematic collection of complexity indicators, } \\
\text { which are used to monitor organizational or even individual } \\
\text { performance. }\end{array}$ \\
\hline Implication & $\begin{array}{l}\text { Increased resistance against development and adaptation of the } \\
\text { complexity measurement systems, along with little usage. }\end{array}$ \\
\hline
\end{tabular}

An overall evaluation of the complexity of a system under scrutiny can be hard to explain, i.e. it is unclear which factors lead to the assessment and why one system is or is not considered complex. This makes it difficult to derive and evaluate key actions to be taken in order to improve system behavior [30].

Table 7. Factor: Inexplicable results

\begin{tabular}{|l|l|}
\hline \multicolumn{2}{|c|}{ 7. Inexplicable results } \\
\hline Description & Complexity assessments are not transparent and hard to explain. \\
\hline Example & $\begin{array}{l}\text { Complexity assessments are represented by a single number. It is } \\
\text { unclear, what exactly this number means or what can be done in } \\
\text { order to reduce or deal with this complexity. }\end{array}$ \\
\hline Implication & $\begin{array}{l}\text { It is not possible to derive actions, which might improve system } \\
\text { behavior and efficiency. }\end{array}$ \\
\hline
\end{tabular}

The seven presented factors are not independent: While most of them positively reinforce each other (e.g. the complexity of the measurement system may result in inconsistent and unclear terminology, and vice versa, unclear terminology makes the measurement system appear more complex) or are unrelated, there are two factors, (1) and (3), which might lead to conflicts: Measurement systems are complex, partly because the underlying measures need to fit to very different objects. Thus a clear method for aggregating different measures into simple results is needed, which reduces the perceived complexity of the measurement system. This is reflected in principle (B), calling for a consistent ontology in the development process.

\section{Principles for the Design of Complexity Measurement Systems}

We now present a set of four principles for the design of complexity measurement systems, which address the factors presented in the previous section. For this, we follow the meta-model of Aier et al. [38]. Even though the context is different-Aier et al. describe a meta-model for principles for enterprise architecture development - the 
resulting artifact matches our requirements: We want to provide "the principles guiding [the] design and evolution" [39] of complexity measurement systems. Furthermore, the underlying theory is well developed.

The principles are presented according to the following structure:

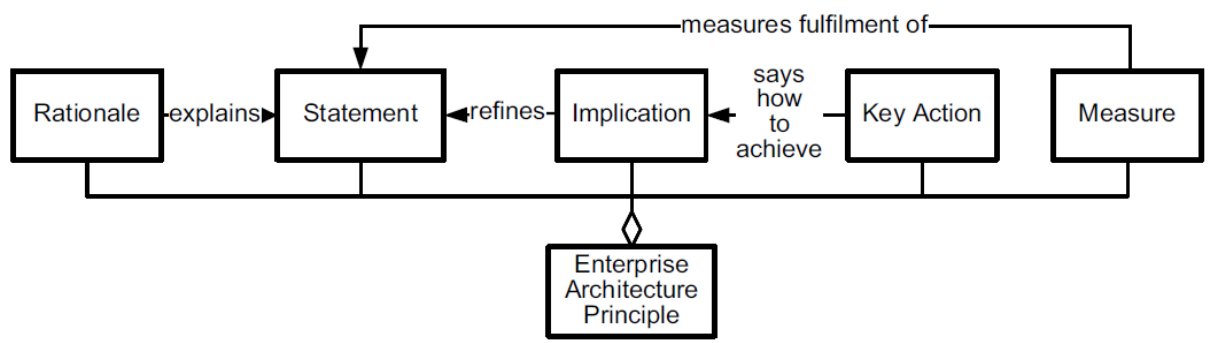

Figure 1. Principle meta-model of Aier et al. (2011)

The statement (what is the goal?) itself is provided, along with the rationale (why should it be done?) behind it. Additionally, we describe measures (how the fulfillment of the principle is measured?) for the successful implementation of the principle and its implications (how can the goal be achieved?), i.e. general actions that follow from the principle. Company and scenario specific key actions (how can it be implemented in a specific case?) are not described, as these vary for each application of the principle [40].

The principles were developed by first analyzing potential solutions to the factors, i.e. what can be done or should have been done to avoid this, and then grouping and aggregating these solutions. This led to four core principles, which should guide the design and adaptation of complexity measurement and management systems:
A. Context-aware design process
B. Consistent ontology
C. Visualization
D. Awareness and support

This process allows for an easy mapping of the principles to the problem factors, which they attempt to address:

Table 8. Mapping the design principles to the addressed problem factors

\begin{tabular}{|c|c|c|c|c|c|c|c|}
\hline & \multicolumn{7}{|c|}{ Factors } \\
\hline \multirow{4}{*}{ 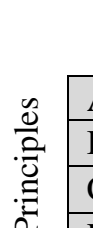 } & 1 & 2 & 3 & 4 & 5 & 6 & 7 \\
\hline & & & $\checkmark$ & $\checkmark$ & & $\checkmark$ & \\
\hline & $\checkmark$ & $\checkmark$ & & & $\checkmark$ & & $\checkmark$ \\
\hline & $\checkmark$ & $\checkmark$ & & & $\checkmark$ & $\checkmark$ & $\checkmark$ \\
\hline$=D$ & & $\checkmark$ & $\checkmark$ & $\checkmark$ & & $\checkmark$ & \\
\hline
\end{tabular}

Following Venable et al. [41], we

- perform an early formative evaluation of these principles

- develop an artifact, which shall be useful for a heterogeneous group of stakeholders 
- analyze socio-technical systems

- do not require strong rigor for our evaluation, as we do not develop a definite system or process, but rather provide guidance for its design [38, 39].

Thus, we select the recommended ex-ante, naturalistic approach to the evaluation of these principles by involving our focus group early during the design phase by paying attention to the applicability for real users and real systems [41]. Different approaches to the measurement of complexity within the participant's organizations were discussed with regard to partially solving the problem factors from the previous section. The proposed principles are therefore a result of an analysis of existing systems and an aggregation of proposed solutions to the problem factors.

Said and King ([42], tables 8 \& 9) identify the following factors as being most important for the usage of an IT system (such as the usage of a complexity measurement system supporting complexity management):

Exogenous factors

1.) Compatibility: Fit of the system to the task performed.

2.) System rating: Perception of the overall characteristics of the system.

3.) Training: Extent of a user's knowledge and expertise with a system. Endogenous factors

4.) Attitudes: How users feel towards the system.

5.) Relative advantage: Degree to which the system is more advantageous to other alternatives.

6.) Ease of use: Perceived usability of the system.

System rating is included in [42] as a general assessment of the quality of an IT-system and therefore not applicable in our case - a resulting principle would just be "build better systems". Relative advantage is also not applicable in the originally proposed sense: As there is usually only one complexity measurement system spanning the entire organization, no viable alternative systems exist. Principle (D) addresses this factor in some sense by explaining the benefits of using a complexity measurement system versus simply relying on intuition. The remaining factors map to the proposed principles: Compatibility is addressed by using a context-aware design process (Principle A) and by using a consistent ontology (Principle B) that explains the relation between the measures and the goals. Attitude is addressed by principle (D). Ease of use is addressed by the visualization principle (C), requiring a simple and easy to understand presentation. We are therefore confident that the proposed principles cover the most important approaches.

The first principle (A) addresses the fact that the targeted entities in an organization differ widely and, related to this, that the target states vary [43]. One needs to be aware of these differences during the design process in order to choose the right approach and tool for the given scenario and intent. This in turn increases the effectiveness of the resulting complexity management system, by ensuring that the measures are related to the goals (3) and are applicable in the specific context (4). It further makes it easier to explain why the measures are relevant (6), as they were chosen with the specific context in mind. 
Table 9. Principle A: Context-aware design process

\begin{tabular}{|c|c|}
\hline \multicolumn{2}{|c|}{ A. Context-aware design process $(3,4,6)$} \\
\hline Statement & $\begin{array}{l}\text { The design and adaptation of complexity measurement systems } \\
\text { needs to be aware of the specific context (goals, measured objects, } \\
\text { target users). }\end{array}$ \\
\hline Rationale & $\begin{array}{l}\text { Depending on the context, certain types of complexity drivers are } \\
\text { good or bad, or relevant or irrelevant and not every measure is } \\
\text { applicable to every object and system. The design of the } \\
\text { measurement system needs to adhere to these external limitations } \\
\text { and requirements. }\end{array}$ \\
\hline Implication & $\begin{array}{l}\text { When designing a complexity measurement system, take the } \\
\text { following into account: } \\
\text { - The specific goals of complexity management for the } \\
\text { evaluated objects } \\
\text { - The targeted users } \\
\text { - The type of objects under scrutiny } \\
\text { - The available data }\end{array}$ \\
\hline Measure & $\begin{array}{l}\text { Indicators for the fulfillment of this principle give information } \\
\text { about the fit of the measurement system on a local level: } \\
\text { - Agreement of domain experts on the relevancy of the } \\
\text { operationalized measures } \\
\text { - Perceived relation between measures and goals } \\
\text { - Average age of available data }\end{array}$ \\
\hline
\end{tabular}

Principle (B) is concerned with the establishment of a consistent ontology, explaining and naming all involved objects, properties and their relations. Complexity in businesses is an issue, which is inherently hard to define and different people with different backgrounds will have a different understanding of what this means in detail. Furthermore, the relation between the targeted goals and the supporting systems is often unclear, inhibiting their usage during transformation: Pombinho criticizes, that "most methods used up to now to manage this complexity are not based on a transversal, coherent and concise conceptual model" [30]. Explaining the relevant objects and relations helps to resolve misunderstandings due to terminology (2) and thus make the resulting complexity management system easier to understand (1). Additionally, knowledge about the relations within the measurement system helps to interpret and explain complexity assessments on a more detailed level (7) and assist in recognizing and resolving inconsistencies (5), both of a technical and terminological nature.

Table 10. Principle B: Consistent ontology

B. Consistent ontology $(1,2,5,7)$

\begin{tabular}{|l|l|}
\hline Statement & $\begin{array}{l}\text { Complexity measures should be based on a consistent ontology, } \\
\text { which names and describes all relevant objects, properties and } \\
\text { their relations. }\end{array}$ \\
\hline Rationale & $\begin{array}{l}\text { This principles stems from two main difficulties (see Section 3): } \\
\text { 1. Complexity is inherently hard to define precisely. }\end{array}$ \\
\hline
\end{tabular}




\begin{tabular}{|c|c|}
\hline & $\begin{array}{l}\text { 2. The relations that lead to a complexity assessment need } \\
\text { to be explained, in order to allow for actionable advice. } \\
\text { These difficulties need to be overcome in order to allow people to } \\
\text { work effectively with the complexity assessments and integrate } \\
\text { them into transformation processes. }\end{array}$ \\
\hline Implication & $\begin{array}{l}\text { - Give a clear definition of relevant objects. } \\
\text { - Describe relations between objects/measures. } \\
\text { - Describe how the measures are related to the goals and to } \\
\text { - Iderall complexity assessments. } \\
\text { - Identify and resolve potential conflicts. }\end{array}$ \\
\hline Measure & $\begin{array}{l}\text { - } \quad \text { Defined terms } \\
\text { - Are aggregated and calculated measures explained? } \\
\text { - Are the measures mapped to the goals? }\end{array}$ \\
\hline
\end{tabular}

Principle (C) states that important results should be visualized in an aggregated, consistent and easy to understand way. While it should still be possible for experts to analyze the details of this aggregate result, a simple, graphical representation, which highlights important information, is essential. This not only hides the inherent complexity of the measurement system itself (1) and thus makes it more accessible for users (6), it also makes it easier to follow a consistent terminology (2) and presentation (5) and to explain and compare results (7).

Table 11. Principle C: Visualization

\begin{tabular}{|c|c|}
\hline \multicolumn{2}{|c|}{ C. Visualization $(1,2,5,6,7)$} \\
\hline Statement & $\begin{array}{l}\text { Results and explanations of complexity assessments should be } \\
\text { presented in a simple, unified and consistent fashion. }\end{array}$ \\
\hline Rationale & $\begin{array}{l}\text { Complexity measurement systems must be accessible for users } \\
\text { from different roles, organizations and with different knowledge. } \\
\text { As such an easy to understand presentation is important. In order } \\
\text { to ease discussion and comparison, this presentation of results } \\
\text { should be consistent across all aggregation levels and contexts. }\end{array}$ \\
\hline Implication & $\begin{array}{l}\text { - Comply with corporate design. } \\
\text { - Use the same format for all reports. } \\
\text { - } \text { Present aggregated and detailed results similarly. } \\
\text { - Highlight important results in an easy graphical way. }\end{array}$ \\
\hline Measure & $\begin{array}{l}\text { - } \quad \text { Number of different templates/designs } \\
\text { - } \quad \text { Percentage of reports, which follow corporate standards } \\
\text { - } \quad \text { Perceived ease of use } \\
\text { - Percentage of reports including simple, aggregated } \\
\text { assessments }\end{array}$ \\
\hline
\end{tabular}

Finally, Principle (D) addresses common issues with acceptance and usage, which result from people not being aware of existing systems and methodological capabilities or from a lack of clear responsibilities for driving the development and usage of complexity measurement systems. Thus, Principle (D) requires a clear plan the 
definition of responsibilities and for raising awareness, both for the necessity and benefits of the measurement and for potential applications of resulting assessments. This insures that irrelevant or misleading measures are detected early and can be corrected (3) along with terminological issues (2). Furthermore, it will be easier to gather support and cooperation (6), and makes it easier to obtain required measures (4).

Table 12. Principle D: Awareness and support

\begin{tabular}{|c|c|}
\hline \multicolumn{2}{|c|}{ D. Awareness and support $(2,3,4,6)$} \\
\hline Statement & $\begin{array}{l}\text { Design of measurement systems needs to be supported by raising } \\
\text { awareness and selecting people, who are responsible for driving } \\
\text { usage and development. }\end{array}$ \\
\hline Rationale & $\begin{array}{l}\text { In order to have an impact, people need to be aware of the } \\
\text { existence and potential applications of the measurement system. } \\
\text { Additionally, the effort involved in the gathering measures needs } \\
\text { to be justified by explaining the resulting benefits. }\end{array}$ \\
\hline Implication & $\begin{array}{l}\text { - Define clear responsibilities. } \\
\text { - } \quad \text { Explain the benefits and potential use cases. } \\
\text { Train people in the usage of the measurement system. }\end{array}$ \\
\hline Measure & $\begin{array}{l}\text { - } \quad \text { Percentage of people aware of the system } \\
\text { - } \quad \text { Percentage of components with clear ownership } \\
\text { - }\end{array}$ \\
\hline
\end{tabular}

\section{$5 \quad$ Discussion and Outlook}

As the development of the principles stems from real-world problems of practitioners, we are confident that these provide a useful guidance for the design of complexity measurement and management systems. The underlying problems do not come from a lack of interest or resources - all companies involved in the focus group employ sophisticated complexity management and reduction programs. The issue lies with actually generating an impact from there: The effect of these systems relies on them being used and supported by people in an organization.

Thus the underlying questions are: How can an understanding of complexity be introduced into a company, so that complexity assessments are used both intuitively and systematically support transformations? How can we guide this series of small, local changes so that it converges to an efficient global state of the business [44]? The proposed principles provide a first point for further discussion in this direction, by giving guidance on the development and adaptation of complexity management systems. Additionally, there are approaches to develop complexity management techniques based on insights from complexity theory, which not necessarily try to reduce complexity, but to manage it in an adequate fashion corresponding to the underlying system complexity [28]. The general problem though is likely not solved by the design and usage of a complexity management system alone, but also has strategic roots $[45,46]$ as well as connections to corporate culture and leadership [47, 48]. Additionally, while still requiring adequate support from complexity measurement 
systems, applying insights from complexity theory to management methods also might help to solve the problem of dealing with complexity [28]. This is outside of the scope of this paper, but presents an interesting area for future, related research.

The presented principles also would benefit from further, more detailed practical evaluation: As the focus groups consisted of enterprise architects and high-level ITmanagers of large companies in different industries, which need to report and justify their investments in complexity management and supporting systems, we believe that the issues of general complexity measurement systems are addressed quite well. Nevertheless, complexity in the context of, for example, company strategy or product design is quite different to IS complexity or organizational complexity and it needs to be analyzed to which extend the principles apply to the former areas $[11,16]$.

\section{References}

1. Miller, D.: Environmental Fit Versus Internal Fit. Organization Science. 3, 159-178 (1992).

2. Vessey, I., Ward, K.: The Dynamics of Sustainable IS Alignment: The Case for IS Adaptivity. Journal of the Association for Information Systems. 14, 283-311 (2013).

3. Dooley, K.J., Van de Ven, A.H.: Explaining Complex Organizational Dynamics. Organization Science. 10, 358-372 (1999).

4. Heywood, S., Spungin, J., Turnbull, D.: Cracking the complexity code. The McKinsey Quarterly. 2, (2007).

5. Shane, J.S., Strong, K.C., Gransberg, D.D.: Project Management Strategies for Complex Projects. (2014).

6. Tanaka, H.: Toward Project and Program Management Paradigm in the Space of Complexity: A Case Study of Mega and Complex Oil and Gas Development and Infrastructure Projects. Procedia - Social and Behavioral Sciences. 119, 65-74 (2014).

7. Anish, S.: Insights from Complexity Theory: Understanding Organizations Better. ISSUES. (2011).

8. Gharajedaghi, J.: Systems thinking: Managing chaos and complexity: A platform for designing business architecture. Elsevier (2011).

9. Pellissier, R.: A Proposed Frame of Reference for Complexity Management as Opposed to the Established Linear Management Strategies. International Journal of Organizational Innovation. 5, 6-67 (2012).

10. Cooke-Davies, T., Cicmil, S., Crawford, L., Richardson, K.: We're Not in Kansas Anymore, Toto: Mapping the Strange Landscape of Complexity Theory, and Its Relationship to Project Management. Project Management Journal. 38, 50-61 (2007).

11. Dewar, R., Hage, J.: Size, Technology, Complexity, and Structural Differentiation: Toward a Theoretical Synthesis. Administrative Science Quarterly. 23, 111-136 (1978).

12. Edmonds, B.: What is Complexity? - The philosophy of complexity per se with application to some examples in evolution. In: Heylighen, F. and Aerts, D. (eds.) The Evolution of Complexity. Kluwer, Dordrecht (1995).

13. Shalizi, P.C.R.: Methods and Techniques of Complex Systems Science: An Overview. In: M.D, T.S.D. and F.A.C.C, J.Y.K. (eds.) Complex Systems Science in Biomedicine. pp. 33114. Springer US (2006). 
14. Bosch-Rekveldt, M., Jongkind, Y., Mooi, H., Bakker, H., Verbraeck, A.: Grasping project complexity in large engineering projects: The TOE (Technical, Organizational and Environmental) framework. International Journal of Project Management. 29, 728-739 (2011).

15. Geraldi, J., Maylor, H., Williams, T.: Now, let's make it really complex (complicated) A systematic review of the complexities of projects. International Journal of Operations \& Production Management. 31, 966-990 (2011).

16. Weidong, Lee: Complexity of Information Systems Development Projects: Conceptualization and Measurement Development. Journal of Management Information Systems. 22, 45-83 (2005).

17. Donde P. Ashmos, Dennis Duchon, Reuben R. McDaniel, J.: Organizational responses to complexity: the effect on organizational performance. Journal of OrgChange Mgmt. 13, 577-595 (2000).

18. Remington, K., Pollack, J.: Tools for Complex Projects. Gower Publishing, Ltd. (2007).

19. Whitty, S.J., Maylor, H.: And then came Complex Project Management. Presented at the 21st IPMA World Congress on Project Management (2007).

20. Whitty, S.J., Maylor, H.: And then came Complex Project Management (revised). International Journal of Project Management. 27, 304-310 (2009).

21. Geraldi, J.G.: What complexity assessments can tell us about projects: dialogue between conception and perception. Technology Analysis \& Strategic Management. 21, 665-678 (2009).

22. Study on: Complexity Management - Chances amid the crisis, http://www.mycomplexity.com/complexity_management_publications/Complexity_Mana gement_Study_Results_sent_internally.pdf, (2009).

23. Peffers, K., Tuunanen, T., Rothenberger, M., Chatterjee, S.: A Design Science Research Methodology for Information Systems Research. J. Manage. Inf. Syst. 24, 45-77 (2007).

24. Fischer, C., Gregor, S., Aier, S.: Forms of Discovery for Design Knowledge. ECIS 2012 Proceedings. (2012).

25. Gregor, S., Hevner, A.R.: Positioning and Presenting Design Science Research for Maximum Impact. MIS Q. 37, 337-356 (2013).

26. Schlindwein, S.L., Ison, R.: Human knowing and perceived complexity: implications for systems practice. Emergence: Complexity and Organization. 6, 27-32 (2004).

27. Ison, R., Schlindwein, S.L.: History repeats itself: current traps in complexity practice from a systems perspective. Presented at the 12th Australia New Zealand Systems Society (2006).

28. Benbya, H., McKelvey, B.: Toward a complexity theory of information systems development. Info Technology \& People. 19, 12-34 (2006).

29. Berry, B.J.L., Kiel, L.D., Elliott, E.: Adaptive agents, intelligence, and emergent human organization: Capturing complexity through agent-based modeling. PNAS. 99, 7187-7188 (2002).

30. Pombinho, J., Aveiro, D., Tribolet, J.: Value-Oriented Specification of Service Systems: Modeling the Contribution Perspective of Enterprise Networks. International Journal of Information Systems in the Service Sector. 7, 60 (2015).

31. Winter, R.: Construction of Situational Information Systems Management Methods: International Journal of Information System Modeling and Design. 3, 67-85 (2012). 
32. Snowden, D.J., Boone, M.E.: A Leader's Framework for Decision Making, (2007).

33. Brown, S.L., Eisenhardt, K.M.: Competing on the Edge: Strategy as Structured Chaos. Harvard Business Press (1998).

34. Yayavaram, S., Chen, W.-R.: Changes in firm knowledge couplings and firm innovation performance: The moderating role of technological complexity. Strat. Mgmt. J. 36, 377396 (2015).

35. Hevner, A., Chatterjee, S.: Design Science Research in Information Systems. Design Research in Information Systems. pp. 9-22. Springer US (2010).

36. Tremblay, M.C., Hevner, A.R., Berndt, D.J.: The Use of Focus Groups in Design Science Research. Design Research in Information Systems. pp. 121-143. Springer US (2010).

37. Siegel+Gale: Global Brand Simplicity Index 2014. Siegel+Gale (2014).

38. Aier, S., Fischer, C., Winter, R.: Construction and Evaluation of a Meta-Model for Enterprise Architecture Design Principles. Wirtschaftsinformatik. p. 51 (2011).

39. TOGAF Version 9.1. The Open Group (2011).

40. Hoogervorst, J.: Enterprise architecture: enabling integration, agility and change. Int. J. Coop. Info. Syst. 13, 213-233 (2004).

41. Venable, J., Pries-Heje, J., Baskerville, R.: A Comprehensive Framework for Evaluation in Design Science Research. In: Peffers, K., Rothenberger, M., and Kuechler, B. (eds.) Design Science Research in Information Systems. Advances in Theory and Practice. pp. 423-438. Springer Berlin Heidelberg (2012).

42. Al-Gahtani, S.S., King, M.: Attitudes, satisfaction and usage: Factors contributing to each in the acceptance of information technology. Behaviour \& Information Technology. 18, 277-297 (1999)

43. Harrison, D.A., Klein, K.J.: What's the Difference? Diversity Constructs as Separation, Variety, or Disparity in Organizations. Academy of Management Review. 32, 1199-1228 (2007).

44. Levinthal, D.A., Warglien, M.: Landscape Design: Designing for Local Action in Complex Worlds. Organization Science. 10, 342-357 (1999).

45. Hoogervorst, J., van der Flier, H., Koopman, P.: Implicit communication in organisations: The impact of culture, structure and management practices on employee behaviour. Journal of Managerial Psychology. 19, 288-311 (2004).

46. Kurtz, C.F., Snowden, D.J.: The new dynamics of strategy: Sense-making in a complex and complicated world. IBM Systems Journal. 42, 462-483 (2003).

47. Lichtenstein, B., Uhl-Bien, M., Marion, R., Seers, A., Orton, J., Schreiber, C.: Complexity leadership theory: An interactive perspective on leading in complex adaptive systems. Management Department Faculty Publications. (2006).

48. Uhl-Bien, M., Marion, R., McKelvey, B.: Complexity Leadership Theory: Shifting leadership from the industrial age to the knowledge era. The Leadership Quarterly. 18, 298318 (2007). 